\title{
Correction to: Characterization and genome sequencing of three Aeromonas hydrophila-specific phages, CF8, PS1, and PS2
}

\author{
Sumeet Rai ${ }^{1}$ - Anuj Tyagi ${ }^{1}$ (D) Anu Kalia ${ }^{2}$ - B. T. Naveen Kumar ${ }^{1} \cdot$ Prince Garg $^{2} \cdot$ Niraj K. Singh $^{3}$
}

Published online: 19 May 2020

(c) Springer-Verlag GmbH Austria, part of Springer Nature 2020

\section{Correction to: Archives of Virology}

https://doi.org/10.1007/s00705-020-04644-0

Authors would like to correct the incorrect version of Fig. 2 in the online publication. Correct version of Fig. 2 is updated here.

\section{Anuj Tyagi}

anujtyaagi@yahoo.co.in

1 College of Fisheries, Guru Angad Dev Veterinary and Animal Sciences University, Ludhiana, Punjab 141004, India

2 Electron Microscopy and Nanoscience Laboratory, Punjab Agricultural University, Ludhiana, Punjab 141004, India

3 School of Animal Biotechnology, Guru Angad Dev Veterinary and Animal Sciences University, Ludhiana, Punjab 141004, India 


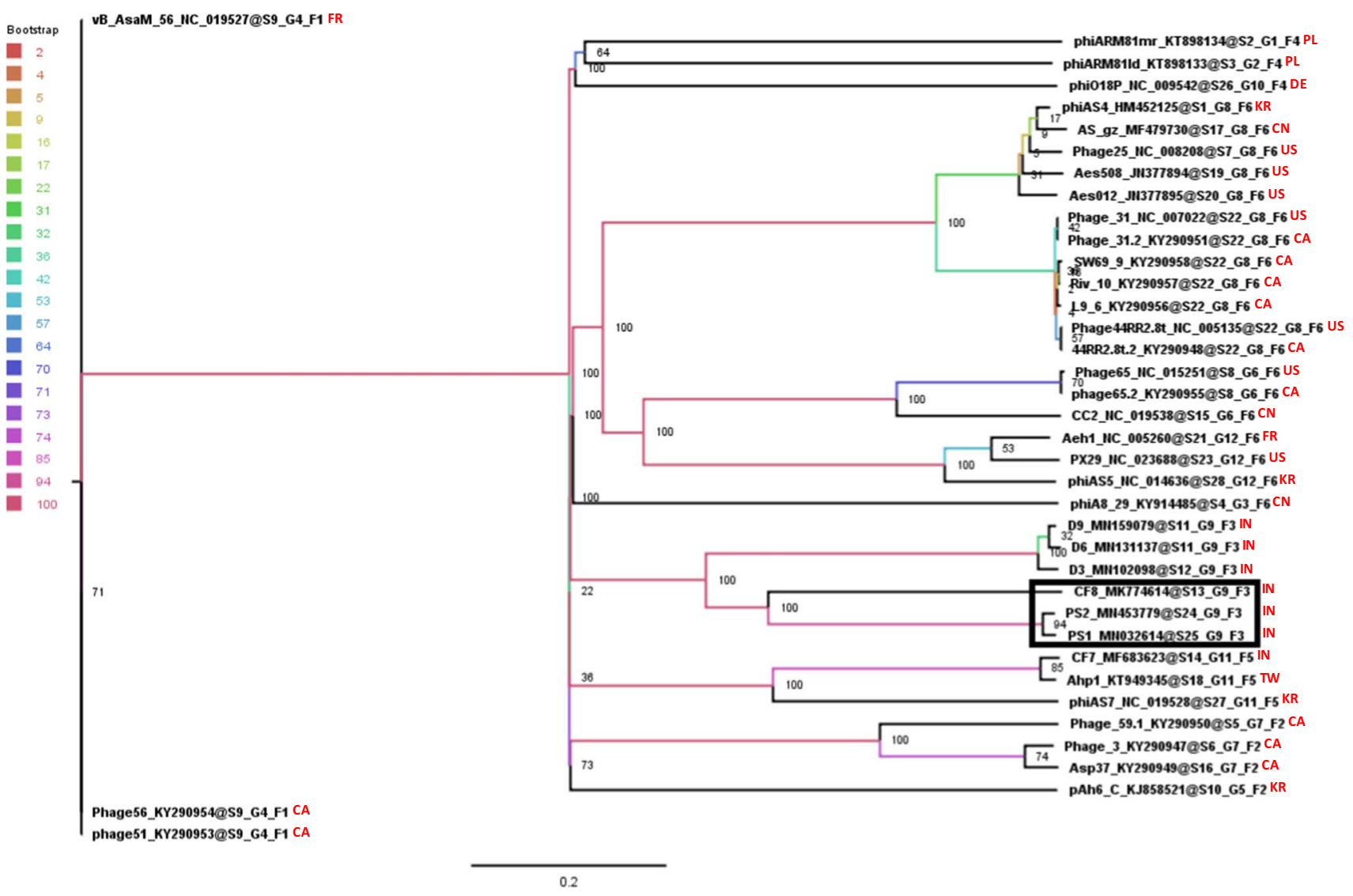

Fig. 2 Genome-based phylogenetic analysis of CF8, PS1, and PS2 phages from this study with other Aeromonas phages genome sequences available in the NCBI database. The branches are coloured based on bootstrap values. Bootstrap values are shown at the nodes. Based on nucleotide sequence similarities, the phages have been clus- tered at the species $(\mathrm{S})$, genus $(\mathrm{G})$ and family $(\mathrm{F})$ level. The scale bar represents 0.2 substitutions per nucleotide. The last two letters (in red) of the branch tip labels indicate the country code. More details about the accession numbers, host, and country of isolation of these phages can be found in Supplementary Table S1

Publisher's Note Springer Nature remains neutral with regard to jurisdictional claims in published maps and institutional affiliations. 